Department of Ophthalmology, University of Nottingham I A El-Ghrably H S Dua G M Orr

P J Tighe

Department of Immunology P J Tighe

Wills Eye Hospital, Philadelphia, USA D Fischer

Correspondence to: I A El-Ghrably, Department of Ophthalmology B Floor, South Block, University Hospital, Queens Medical Centre, Nottingham NG7 2UH

Accepted for publication 28 July 1999

\title{
Detection of cytokine mRNA production in infiltrating cells in proliferative vitreoretinopathy using reverse transcription polymerase chain reaction
}

\author{
I A El-Ghrably, Harminder S Dua, Gavin M Orr, David Fischer, Patrick J Tighe
}

\begin{abstract}
Aims-To determine whether the infiltrating cells in the vitreous and subretinal fluid of patients with proliferative vitreoretinopathy (PVR) express messenger RNA for various cytokines found in this condition.

Methods-The presence of mRNA coding for HPRT, IL-6, IL-1 $\beta$, IL-8, and TNF $\alpha$ was investigated in 20 vitreous and subretinal fluid (SRF) samples from patients with PVR by reverse transcriptase polymerase chain reaction (RT-PCR). 16 samples from patients with retinal detachment and macular holes were used as controls.
\end{abstract}

Results-HPRT was detected in all samples of PVR and in $11(69 \%)$ control cases. Patients with PVR demonstrated mRNA for the cytokines tested more often than controls. The difference was statistically significant.

Conclusion-The presence of mRNA encoding for IL-6, IL-1 $\beta$, IL-8, and TNF $\alpha$ is significantly detected by RT-PCR in vitreous and SRF samples of patients with PVR, indicating local production of these cytokines by vitreous and SRF cells.

(Br f Ophthalmol 1999;83:1296-1299)

Proliferative vitreoretinopathy (PVR) is a process of cellular proliferation and contraction that complicates rhegmatogenous retinal detachment. PVR is the most common cause of failure when the primary break has been appropriately treated. ${ }^{12}$ The exact pathogenic mechanisms involved in the formation of PVR are not completely understood. However, five distinct stages appear to be important in its development including breakdown of the blood-retinal barrier (BRB), chemotaxis and cellular migration, cellular proliferation, membrane formation, and contraction. ${ }^{3-5}$

It is believed that different cytokines, produced as a consequence of immune or inflammatory reactions, are involved in the pathogenesis of PVR..$^{6-9}$ Cytokines such as interleukin 1 (IL-1), interleukin 6 (IL-6), tumour necrosis factor $\alpha(\mathrm{TNF} \alpha)$, interferon $\gamma(\mathrm{IFN} \gamma)$, interleukin 8 (IL-8), and monocyte chemotactic protein 1 (MCP-1) have been detected in the vitreous samples as well as epiretinal membranes obtained from PVR patients. ${ }^{10-15}$

It is not known whether these cytokines are produced locally by the cells infiltrating the vitreous or diffuse into the vitreous cavity following a breakdown of the BRB. We therefore tested the infiltrating cells in vitreous obtained from patients with PVR, for mRNA encoding for HPRT (housekeeping gene), IL-1 $\beta$, IL-6, $\mathrm{TNF} \alpha$, and IL-8.

\section{Materials and methods}

VITREOUS AND SRF SPECIMENS

Twelve vitreous and eight subretinal fluid (SRF) samples were obtained by vitrectomy from 18 patients with PVR (both vitreous and SRF were obtained from two patients). Ten vitreous samples obtained from patients with macular hole and six vitreous samples from patients with retinal detachment (RD), not complicated by PVR, were examined as a control group. The presence of mRNA coding for HPRT, IL-6, IL-1 $\beta$, TNF $\alpha$, and IL- 8 was investigated by reverse transcriptase polymerase chain reaction (RT-PCR).

The severity of PVR was graded according to the criteria of the Retina Society Terminology Committee. ${ }^{2}$ Samples were obtained through conventional three port closed vitrectomy technique by manual suction before opening the infusion line. SRF samples were obtained during the drainage procedure with a Charles flute needle connected to a $1 \mathrm{ml}$ syringe with a side port. Samples with vitreous haemorrhage were excluded from the study. The study complied with the declaration of Helsinki.

mRNA EXTRACTION AND CDNA SYNTHESIS

Cellular pellets were obtained from the samples by centrifugation and mRNA extracted using Qiagen RN easy (UK) method following the manufacturer's procedure. Eluted RNA was made up to $50 \mu \mathrm{l}$ with DEPC water and cDNA was prepared using Oligo-(dT) priming in ready to go cDNA synthesis tubes (Pharma- 
Table 1 Number of vitreous and SRF samples that were positive for presence of $m R N A$ for the different cytokines tested

\begin{tabular}{llllll}
\hline & HPRT & IL-6 & IL1- $\beta$ & TNFa & IL-8 \\
\hline Sample & & & & & \\
Vitreous (12) & $(12) 100 \%$ & $(10) 83 \%$ & $(6) 50 \%$ & $(6) 50 \%$ & $(9) 75 \%$ \\
SRF (8) & $(8) 100 \%$ & $(6) 75 \%$ & $(6) 75 \%$ & $(4) 50 \%$ & $(6) 75 \%$ \\
Total (20) all samples & $(20) 100 \%$ & $(16) 80 \%$ & $(12) 60 \%$ & $(10) 50 \%$ & $(15) 75 \%$ \\
Controls & & & & & $(1) 10 \%$ \\
MH (10) & $(5) 50 \%$ & $(2) 20 \%$ & $(1) 10 \%$ & $(0) 0 \%$ & $(2) 33 \%$ \\
RD (6) & $(6) 100 \%$ & $(2) 33 \%$ & $(0) 0 \%$ & $(1) 16.5 \%$ & $(3) 18.75 \%$ \\
Total (16) control & $(11) 68.75 \%$ & $(4) 25 \%$ & $(1) 6.25 \%$ & $(1) 6.255$ & \\
\hline
\end{tabular}

SRF = subretinal fluid, $\mathrm{MH}=$ vitreous from macular hole patients, $\mathrm{RD}=$ vitreous from retinal detachment patients. Primers used: HPRT 5'GACCAGTCAACAGGGGACAT/3'CGACCTTGACCATCTTTGGA (160 base pairs), IL-6 5'AGGTTGTTTTCT GCCAGTGC/3'CACACAGACAGCCACTCACC (145 base pairs), IL-1 $\beta$ 5'AGCCATGGCAGAAGTACCTG/3'CATCTG TTTAGGGCCATCAG (100 base pairs), TNF $\alpha$ 5'CACCACGCTCTTCTGCCT/3'TCTCAGCTCCACGCCATT (225 base pairs), IL-8 5'AAGAAACCACCGGAAGGAAC/3'TGTGGTCCACTCTCAATCACTC (218 base pairs).

cia Biotech, UK) following the manufacturer's procedure. Peripheral blood mononuclear cells (PBMC) stimulated with phytohaemagglutinin (PHA) (Sigma) were prepared by a standard method to serve as our positive control. Cloned PCR products of each cytokine were used as another positive control. These clones (in pNEB 193) have a 5 bp internal deletion generated by PCR mutagenesis for other purposes (P J Tighe, unpublished data). These were used at 1000 single stranded copies/PCR for positive control purposes.

PRIMERS

Primers used were designed using the program primer 3 at: http://www.genome.wi.mit.edu/ cgi-bin/primer/primer3.cgi. All primers were cross checked against the Genbank database to ensure no cross reactivity with other human sequences (Table 1), and verified to amplify only cDNA.

PCR AMPLIFICATION

PCR was performed using standard agents (buffers from Invitrogen UK, dNTPs from Sigma, Poole UK, and Ampli Taq Gold from Perkin Elmer, Warrington) for 35-37 cycles using a Progene instrument from Techne (UK). PCR product was subjected to electrophoresis on $2 \%$ agarose gel, stained with ethidium bromide and visualised by ultraviolet illumination (Fig 1).
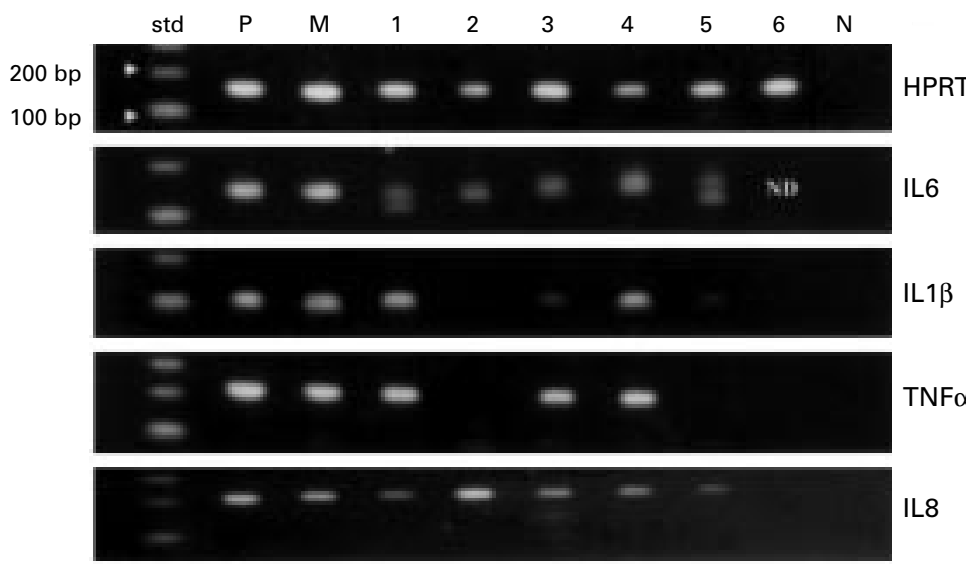

Figure 1 Agarose gel (2\%) showing an example of polymerase chain reaction products generated by specific primers for HPRT, IL-6, IL-1 $\beta$, TNFa, and IL-8 using vitreous samples from patients with PVR. Std $=100 \mathrm{bp} D N A, N D=$ not determined, $P=$ positive control (PBMC), $M=$ mimic (2nd positive control), $N=$ negative control, $1-6$ represent vitreous samples.
The $\chi^{2}$ test (statistics program, sPss for Windows) was used to test for significance between presence of cytokines in the PVR samples versus the control group.

\section{Results}

HPRT mRNA was detected in all samples from PVR (100\%) and in 11 of 16 control samples $(69 \%)$. Of the 20 samples of PVR, IL-6 mRNA was detected in 16 samples $(80 \%),(10 / 12$ vitreous $(83 \%)$ and $6 / 8 \mathrm{SRF}$ $(75 \%))$. IL- $1 \beta$ mRNA was detected in 12 samples $(60 \%)(6 / 12$ vitreous $(50 \%)$ and $6 / 8$ SRF $(75 \%))$. TNF $\alpha$ mRNA was detected in 10 samples $(50 \%)(6 / 12$ vitreous $(50 \%)$ and $4 / 8$ SRF (50\%)). IL-8 mRNA was detected in 15 samples $(75 \%)(9 / 12$ vitreous $(75 \%)$ and $6 / 8$ SRF $(75 \%))$. In all, seven samples were positive for all cytokines tested. Six of the seven patients who tested positive for all cytokines had PVR graded between $\mathrm{C}_{2}$ and $\mathrm{D}_{1}$.

Only a small proportion of samples from the control group tested positive for cytokine mRNA. Four out of 16 (25\%) were positive for IL-6, one $(6.25 \%)$ for IL- $1 \beta$, one $(6.25 \%)$ for $\mathrm{TNF} \alpha$, and three $(18.75 \%)$ for IL-8 (Table 1 ). This difference in the presence of cytokine mRNA between samples from the PVR group and the control group, for each cytokine tested, was highly significant $(\mathrm{p}=0.00097,0.00085$, 0.00080 , and 0.00463 , for IL-6, IL-1 $\beta$, IL-8, and $\mathrm{TNF} \alpha$ respectively).

\section{Discussion}

The results obtained from RT-PCR analysis of vitreous and SRF samples from patients undergoing vitrectomy for PVR provide evidence for the expression of mRNA for IL-6, IL- $1 \beta$, TNF $\alpha$, and IL- 8 .

Previous studies ${ }^{10-15}$ have been based on the detection of protein secretion and quantitation using bioassay and enzyme labelled immunosorbent assay (ELISA) techniques. Bioassays which measure functional properties, depending on the responsiveness of indicator cells lines, are technically restrictive. ${ }^{16}$ These techniques require in vitro stimulation, which could result in distortion of the true in vivo response. ${ }^{17}$ Techniques based on ELISA are highly specific but do not distinguish between biologically active or inactive substances. Furthermore, these assays determine the extracellular presence of a secreted interleukin, reflecting the net outcome of produced, absorbed, and degraded cytokine. ${ }^{18}$ 
Our approach to the role of cytokines in PVR pathogenesis was to directly detect cytokine mRNA from cells within the vitreous and SRF. This approach provides information on the possibility of local production of the cytokines in question, within the vitreous cavity, by the infiltrating cells. In addition, analysis of mRNA can detect the presence of a cytokine which may be absent in culture supernatants due to uptake and utilisation by cells bearing receptors. Thus, mRNA profiles can provide fairly accurate account of potential cytokine production. ${ }^{16}$ On the downside, however, the presence of cytokine mRNA does not guarantee that it will be translated. Potential regulation at transcriptional, post-transcriptional, translational, and post- translational levels may occur. ${ }^{19}$

To our knowledge the only work to detect the presence of cells expressing mRNA coding for IL-6, IL-1 $\beta, \mathrm{TNF} \alpha$ in epiretinal membranes from patients with PVR was carried out by Limb et al. ${ }^{20}$ They used an in situ hybridisation technique which, although sensitive, is technically very demanding to quantify. Owing to the different distribution of cytokines between the vitreous and epiretinal membranes in patients with PVR, ${ }^{11}$ the above study data did not provide information on cytokine production in the vitreous. This information was obtained by our approach. Both studies, however, have a similar drawback in that the demonstration of mRNA does not necessarily imply the presence of the protein product. RT-PCR was used because of its sensitivity, specificity, and its particular value where a limited amount of tissue is available and small amounts of cells express the gene of interest.

The majority of cells present in the vitreous samples of patients with PVR are capable of producing cytokines in vitro. RPE cells, upon activation, release IL-8, IL-6, and granulocyte macrophage colony stimulating factor. ${ }^{21-23}$ Glial cells produce IL-1. ${ }^{8}$ Macrophages and T lymphocytes produce many different cytokines including IL-1, IL-6, TNF $\alpha$, and IFN $\gamma \cdot{ }^{24}$ The actual role of cytokines in the pathogenesis of PVR is not clear, but their involvement in regulating immune and inflammatory responses is well described. ${ }^{19}$ In the retinal microenvironment, they could contribute substantially to the occurrence of PVR.

This study, like that of Kauffmann et $a l^{12}$ and Elner et $a l^{13}$ demonstrated a consistent presence of IL- 6 and IL- 8 in samples obtained from PVR patients. The definitive role of IL- 8 in the pathogenesis of PVR is not clear, but owing to its chemotactic activity for leucocytes, it was postulated that TNF $\alpha$ and IL- $1 \beta$, which were not directly chemotactic for leucocytes, exert their chemotactic effect through induction and release of secondary cytokines including IL-8 and MCP- $1 .{ }^{13}$ Both IL-1 and IL-6 mediate inflammatory cell functions such as cell growth, migration, and differentiation. They overlap in their functions, and IL- 1 is a potent inducer of IL- 6 expression in many cell types. $^{25} 26$

Although some patients with macular holes had epiretinal membrane (ERM), the macular hole group did not show the same cytokine profiles as did the PVR patients. This may be due to difference in the composition of ERM in macular holes. ERM is primarily a glial reaction with few inflammatory cells and lymphocytes. ${ }^{27}$

In conclusion, our data indicate that mRNA encoding for IL-6, IL- $1 \beta, \mathrm{TNF} \alpha$, and IL- 8 is significantly detected by RT-PCR in vitreous and SRF samples of patients with PVR, indicating probable local production of these cytokines by vitreous and SRF cells and their possible role in pathogenesis of the disease. Further work is needed to correlate the level of mRNA to respective cytokines in the vitreous and to severity of the disease and prognostic outcome of surgery.

The authors wish to acknowledge the help of Ms Sue Stevens, Mrs Jennie Phillips, and Dr A Azuara-Blanco. Supported by a grant from the Uveitis Foundation, Wills Eye Hospital, Philadelphia and the government of Egypt (IA El-Ghraby).

1 Machemer R. Proliferative vitreoretinopathy (PVR): a achemer R. Proliferative vitreoretinopathy (PVR): a personal account of its pathogenesis a
Ophthalmol Vis Sci $1988 ; 29: 1771-83$.

2 The Retina Society Terminology Committee. The classification of retinal detachment with proliferative vitreoretinopathy. Ophthalmology 1983;90:121-5.

3 Wiedemann P, Weller M. The pathophysiology of proliferative vitreoretinopathy. Acta Ophthalmol 1988;189:(Suppl) $7-15$

4 Ryan SJ. The pathophysiology of proliferative vitreoretinopathy in its management. Am f Ophthalmol 1985;100:188-

5 Smith-Thomas L, Haycock JW, Metcalfe R, et al. Involvement of calcium in retinal pigment epithelial cell proliferation and pigmentation. Curr Eye Res 1998;8:813-22.

6 Baudouin C, Fredj-Reygrobellet D, Gordon WC, et al. Immunohistochemical study of epiretinal membranes in proliferative vitreoretinopathy. Am $\mathcal{F}$ Ophthalmol 1990;110: prolifer

7 Esser P, Heimman K, Wiedemann P. Macrophage in proliferative vitreoretinopathy and proliferative diabetic retinopathy: differentiation of subpopulation. Br F Ophthalmol 1993;77:731-3.

8 Roberge FG, Caspi RR, Nussenblatt RB. Glial retinal Muller cells produce IL-1 activity and have a dual effect on autoimmune T helper lymphocytes. F Immunol 1988;140: 2193-6.

9 Planck SR, Huang X-N, Robertson JE, et al. Retinal pigment epithelial cells produces IL- $1 \beta$ and granulocytemacrophage colony stimulating factor in response to IL- $1 \alpha$. Curr Eye Res 1993;12:205-12.

10 Limb GA, Little BC, Meager A, et al. Cytokines in proliferative vitreoretinopathy. Eye 1991;5:686-93.

$11 \mathrm{Limb}$ GA, Alam A, Early O, et al. Distribution of cytokine proteins within epiretinal membranes in proliferative vitreoretinopathy. Curr Eye Res 1994;13:791-8.

12 Kauffmann DJ, Meurs JC, Mertens DA, et al. Cytokine in vitreous humor: interleukin-6 is elevated in proliferative vitreoretinopathy. Invest Ophthalmol Vis Sci 1994;35:900-6.

13 Elner SG, Elner VM, Jaffe GJ, et al. Cytokines in proliferative diabetic retinopathy and proliferative vitreoretinopathy. Curr Eye Res 1995;1045-53.

14 Abu El-Asrar AM, Damme JV, Put W, et al. Monocyte chemotactic protein-1 in proliferative vitreoretinal disorders. Am f Ophthalmol 1997;123:599-606.

15 Nagasaki H, Kouichi S. Risk factors for proliferative vitreoretinopathy. Curr Opin Ophthalmol 1995;6:70-5.

16 Carding SR, Dandan Lu, Bottomly K. A polymerase chain detection assay for the detection and quantitation of cytokine gene expression in small numbers of cells. F Immunol Meth 1992;151:277-87.

17 Feldmann M, Brennan FM, Chantry D, et al. Cytokine assays: role in evaluation of the pathogenesis of autoimmuassays: role in evaluation of the patho
nity. Immunol Rev 1991;119:105-23.

18 Birgitta S, Andersson J, Andersson U. Assessment of cytokines by immunofluorescence and the paraformaldehyde-saponin procedure. Immunol Rev 1991; 119:66-93.

19 Dallman MJ, Montgomery RA, Larsen CP, et al. Cytokine gene expression: analysis using northern blotting, polymerase chain reaction and in situ hybridisation. Immunol Rev 1991;119:163-79.

20 Limb GA, Earley O, Jones SE, et al. Expression of mRNA coding for TNF $\alpha$, IL-1 $\beta$, and IL- 6 by cells infiltrating retinal membranes. Graefes Arch Clin Exp Ophthalmol 1994; 232: $646-52$.

21 Elner VM, Strieter RM, Elner SG, et al. Neutrophil chemotactic factor (IL-8) gene expression by cytokine treated
retinal pigment epithelial cells. Am f Pathol 1990;136:74550 . 
22 Elner VM, Scales W, Elner SG, et al. Interleukin 6 (IL-6) gene expression and secreation by cytokine stimulated human retinal pigment epithelial cells. Exp Eye Re 1992;54:361-8.

23 Jaffe GJ, Roberts WL, Wong HL, et al. Monocyte induced cytokine expression in cultured human retinal pigment epithelial cells. Exp Eye Res 1995;60:533-43.

24 Balkwill FR, Burke F. The cytokine network. Immunol Today 1989;10:299-303.
25 Mantovani A, Dejana E. Cytokines as communication signals between leucocytes and endothelial cells. Immunol Today 1989;10:370-5.

26 De Vos AF, Hoekzema R, Kijlstra A. Cytokines and uevitis, a review. Curr Eye Res 1992;11:581-97.

27 Chignell AH, Wong D. Macular surgery. Macular hole. In: Chignell AH, Wong D, eds. Management of vitreoretinal diseases. A surgical approach. London: Springer-Verlag, 1999: $171-80$. 